\title{
O uso do Geogebra como ferramenta para a construção de conceitos matemáticos: um primeiro estudo envolvendo Cadeias de Markov
}

\author{
Rodrigo Sychocki da Silva - rodrigo.silva@ caxias.ifrs.edu.br - PPGIE - UFRGS/IFRS \\ Dante Augusto Couto Barone - barone@ inf.ufrgs.br - INF/PGIE - UFRGS \\ Marcus Vinicius de Azevedo Basso - mbasso@ufrgs.br - IM - UFRGS
}

\begin{abstract}
Resumo: Esse trabalho apresenta os resultados de uma sequência de atividades realizada com alunos de graduação em matemática e também com professores de matemática da região de Passo Fundo (RS). Através de uma metodologia de trabalho fundamentada na Engenharia Didática, a exploração de uma situação-problema inicial envolvendo Cadeias de Markov ${ }^{l}$, conduziria os participantes em um processo de elaboração e verificação de hipóteses matemáticas. A análise das produções ocorre à luz da teoria da abstração reflexionante proposta por Piaget, onde através de passos sucessivos os sujeitos elaboram, constroem e reconstroem conceitos de matemática durante a sequência de atividades. A utilização do objeto virtual apontou que a construção dos conceitos ocorre de forma gradual e é potencializada com o uso da tecnologia.
\end{abstract}

Palavras Chave: Abstração reflexionante, engenharia didática, modelagem matemática, tecnologia

\section{The use of Geogebra as a tool for the construction of mathematical concepts: a first study of Markov Chains}

\begin{abstract}
This paper presents the results of a sequence of activities carried out with undergraduate students in mathematics and also with mathematics teachers in the region of Passo Fundo (RS). Through a methodology based on the Engineering Curriculum, exploitation of an initial problem situation involving Markov chains, lead participants in a process of development and verification of mathematical hypotheses. The analysis of the production occurs in the light of the theory of reflective abstraction proposed by Piaget, which through successive steps subjects elaborate, construct and reconstruct math concepts during the following activities. The use of virtual object pointed out that the construction of the concepts occurs gradually and is enhanced with the use of technology.
\end{abstract}

Keywords: Reflective abstraction, didactic engineering, mathematical modeling, technology.

\section{Introdução \\ Brasil (2000) afirma:}

A matemática deve ser vista pelo aluno como um conjunto de técnicas e estratégias para serem aplicadas a outras áreas do conhecimento, assim como

\footnotetext{
${ }^{1}$ Nome dado em homenagem ao matemático russo Andrei Andreyevich Markov que as criou inicialmente em 1907.
} 
para a atividade profissional. Não se trata de os alunos possuírem muitas e sofisticadas estratégias, mas sim de desenvolverem a iniciativa e a segurança para adaptá-las a diferentes contextos, usando-as adequadamente no momento oportuno. Nesse sentido, é preciso que o aluno perceba a Matemática como um sistema de códigos e regras que a tornam uma linguagem de comunicação de ideias e permite modelar a realidade e interpretá-la. Assim, os números e a álgebra como sistemas de códigos, a geometria na leitura e interpretação do espaço, a estatística e a probabilidade na compreensão de fenômenos em universos finitos são subáreas da Matemática especialmente ligadas às aplicações. (Brasil, 2000, p.40)

A manifestação de uma matemática aplicada ao cotidiano dos alunos conforme apresentado anteriormente emerge no cenário das diferentes modalidades de ensino. Muitas vezes o conhecimento matemático apresentado aos alunos é tratado como isolado e sem relação com os demais, tornando a matemática uma ciência isolada e sem sentido. Concebemos que seja necessária e suficiente que a ação e o trabalho cognitivo sobre os objetos de estudo possibilitem aos alunos a evolução da compreensão e construção dos conceitos matemáticos abordados na sala de aula.

Alguns trabalhos científicos envolvendo metodologias de ensino das Cadeias de Markov já foram produzidos no Brasil, destacamos aqui três pesquisas. Silva (2013, p.41) em sua pesquisa de mestrado aponta que "uma pergunta freqüente dos alunos numa sala de aula de matemática, é onde se aplica o assunto estudado". Nesse sentido, sua pesquisa procurou apresentar possibilidades para o ensino de matrizes e sistemas lineares, com aplicação das Cadeias de Markov na modelagem de problemas nas áreas de genética, psicologia e transporte ferroviário.

Ainda sobre o aspecto da aplicabilidade da matemática, Ferreira (2013) apresenta em sua dissertação aplicações da matemática que envolve matrizes, com o objetivo de qualificar o trabalho do professor que atua na sala de aula. Segundo a autora:

O professor de matemática tem encontrado grande dificuldade ao trabalhar com alguns conceitos dentro da sala de aula, no que diz respeito a utilidade de tais assuntos. E muitas vezes o aluno é desestimulado, pois desenvolve a matemática de maneira mecânica, sem saber sua real função no cotidiano. (Ferreira, 2013, p.55)

Nesse aspecto, Biasi e Domenech (2012) apontam que:

(...) o desenvolvimento de uma ferramenta de software que auxiliasse no processo de ensino-aprendizagem de métodos estocásticos, mostrando e complementando, de forma visual, prática e passo-a-passo (estudo dirigido) os conceitos discutidos em sala de aula. Essa complementação é relevante, pois muitas vezes os conceitos que não são satisfatoriamente entendidos, podem ser retomados ou reforçados em um laboratório com o auxílio de uma ferramenta especializada, que além de exemplificar conceitos da teoria, pode proporcionar ao aluno que ele pratique o que foi discutido em sala de aula. (Biasi e Domenech, 2012, p.37)

A proposta dos autores vem ao encontro de nossa concepção sobre a importância do recurso computacional como fonte para a construção do conhecimento. Os alunos envolvidos em um ambiente computacional onde a modelagem é realizada simultaneamente e os resultados obtidos podem ser analisados e interpretados fornecem evidências para uma aprendizagem de qualidade. Concebemos que a construção de 
hipóteses e validação das mesmas em um ambiente informatizado é potencializada pelo uso da tecnologia. Ao mudar na tela do computador os parâmetros e condições do problema, os alunos têm a possibilidade de confrontar e validar suas hipóteses, através da construção e manutenção de argumentos matemáticos, evidenciando sua aprendizagem.

Neste aspecto, a teoria da abstração reflexionante proposta por Piaget é utilizada na atual pesquisa com o propósito de fornecer os subsídios necessários para a análise da produção dos alunos como também permitir a compreensão da evolução cognitiva dos mesmos durante a realização das atividades. Nota-se que o uso do objeto virtual possibilitou a elaboração e construção de diversas hipóteses e conceitos de matemática durante as atividades, onde através da ação dos sujeitos sobre o objeto virtual foi possível identificar o exercício da abstração reflexionante.

O texto está estruturado em cinco seções. Na seção 2 é explorado o conceito de abstração proposta por Piaget, em particular o da abstração reflexionante, o qual constitui uma importante fonte para análise da produção dos alunos. Na seção 3 é apresentada a Engenharia Didática como proposta de trabalho presente para a atual pesquisa. Na seção 4 são discutidos os procedimentos metodológicos ocorridos durante a execução das atividades, evidenciando as etapas de realização e estabelecendo possíveis conexões entre o uso da tecnologia e as atividades propostas. Na seção 5 são apresentados e discutidos os resultados obtidos com a aplicação da sequência de atividades, bem como as relações com a fundamentação teórica utilizada para a interpretação dos dados. E finalmente, na seção 6, apresentamos algumas conclusões parciais para o trabalho, destacando que o uso do objeto virtual foi um catalisador na elaboração, construção e compreensão dos conceitos matemáticos.

\section{O papel da abstração na construção de conceitos}

A epistemologia genética de Jean Piaget é a teoria que explica o desenvolvimento cognitivo humano levando em consideração as ações do sujeito sobre os objetos e os seus avanços progressivos, devido às coordenações das ações realizadas pelo sujeito ao agir sobre os objetos. Na epistemologia genética considera-se "objeto" tudo o que não é o sujeito. É importante destacar que o pensamento e as ideias do próprio sujeito também podem ser considerados objetos, desde que o sujeito estabeleça ações sobre eles e assim avance na direção da tomada de consciência.

O termo "coordenações de ações" apresentado no parágrafo anterior é a fonte de estudo no processo de abstração proposto por Piaget (1977). O verbo abstrair significa retirar, extrair, puxar, neste caso temos que a abstração consiste no processo de retirada de qualidades dos objetos ou também a retirada de uma elaboração através das coordenações de ações sobre os objetos. Nesse sentido, a abstração proposta por Piaget divide-se em duas categorias: abstração empírica e abstração reflexionante.

A abstração empírica consiste em extrair dos objetos qualidades que eles possuem, onde através delas o sujeito terá a possibilidade de fazer relações e elaborar novas características ou qualidades para os objetos. Podemos dizer que a abstração empírica é a etapa inicial e necessária para a evolução cognitiva do sujeito, uma vez que sem ela não é possível evoluir a qualidade do pensamento através da abstração reflexionante. No processo de retirada das características dos objetos não podemos confundir isso com a retirada de qualidades que atribuímos aos objetos, caracterizando segundo Piaget (1977) a abstração pseudo-empírica. A abstração pseudo-empírica é um 


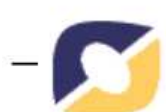

tipo de abstração reflexionante e exige do sujeito a coordenação de suas ações para acontecer.

Conforme dito anteriormente, o processo de abstração empírica é necessário para que o sujeito evolua cognitivamente. Porém, somente com esse tipo de abstração não é possível dar conta nas explicações sobre os processos de generalizações, conforme a matemática propõe. Na matemática a empiria se faz presente, ao passo que a extração das características próprias dos objetos é necessária e contribui para elaborações mais complexas e que generalizam as qualidades, enriquecendo assim o objeto de estudo. À medida que se aumenta o número de abstrações do sujeito durante o processo interativo com o objeto, a qualidade de seu pensamento evolui devido à abstração reflexionante e as sucessivas tomadas de consciência durante o processo.

No estudo da tomada de consciência, Piaget mostra que a tomada de consciência possui níveis que progressivamente evoluem conforme aumenta a intensidade da interação entre sujeito e objeto. Podemos afirmar que esses níveis estão em correspondência biunívoca com o processo de abstração, ao passo que a abstração caracterizada pela tomada de consciência do sujeito é chamada de abstração refletida. Essa última é o produto de uma abstração reflexionante que se tornou consciente para o sujeito. Os diversos experimentos apresentados em Piaget (1977) mostram que para atingir esse patamar de abstração o sujeito deve passar por etapas que são necessárias e graduais, onde a cada novo desafio o sujeito é desequilibrado e deve se organizar de tal forma a superar as contradições e dificuldades que surgem na interação.

Nesse sentido, o processo de abstração está intimamente ligado com os processos de assimilação e acomodação propostos por Piaget em sua teoria da equilibração. Piaget considera que esses dois elementos são os pólos da interação entre o sujeito e o objeto, na qual é condição necessária e suficiente para o desenvolvimento intelectual. Novamente, Montangero (1998) argumenta que a assimilação não se reduz a uma simples identificação, mas sim à construção de estruturas que incorporam novos elementos ao longo do processo. A acomodação nesse sentido surge como atividade complementar da assimilação na qual é exercida pelo sujeito e consiste na reorganização dos seus esquemas assimiladores, produzindo assim uma estrutura. A estrutura caracteriza-se como uma organização de esquemas assimiladores capazes de possibilitar ao sujeito enfrentar as diversas situações.

Quando o sujeito está frente às situações novas, Piaget (1977) em sua teoria da abstração propõe a "criação das novidades" como característica essencial da abstração reflexionante. O processo de "criar novidades" frente aos desafios é uma característica essencialmente dos seres humanos, pois ao possuir a capacidade simbólica, construída desde o estádio pré-operatório, os humanos podem estabelecer relações entre os seus esquemas e a organização do pensamento em forma simbólica possibilita que essas relações sejam cada vez mais aprimoradas e melhorem a qualidade do pensamento.

O processo de abstração aponta características fundamentais para a compreensão de como o sujeito evolui cognitivamente. O aperfeiçoamento das qualidades no pensamento depende de dois processos internos que ocorrem durante o processo de acomodação: reflexão e reflexionamento. Esses dois processos são essenciais para compreender como a evolução do pensamento humano ocorre endogenamente.

O reflexionamento pode ser entendido como o ato mental de projetar um patamar inferior para um superior, ou seja, é um processo que leva características de um nível precedente para um próximo. Essa passagem não explica o aperfeiçoamento qualitativo do pensamento, sendo assim necessário que ocorra a reflexão. A reflexão 
para Piaget é o ato mental capaz de reconstruir e reorganizar os elementos que vieram do patamar anterior. A reflexão e o reflexionamento não ocorrem isoladamente, ambos caracterizam um processo necessário na evolução do processo de abstração. $O$ aperfeiçoamento da estrutura, provinda da organização dos esquemas possibilita ao sujeito conforme ele avança na ação, organizar e aprimorar também a sua reflexão.

Juntamente com a criação das novidades, o processo de reflexionamento e reflexão caracterizam o processo de evolução da abstração. Como Piaget (1977) afirma, a acomodação propõe que o sujeito terá um equilíbrio cognitivo, não permanente, mas ao ser colocado frente a uma situação nova que exige a criação de novidades, o sujeito é colocado em prova e diante dos fatos, ele pode através das coordenações de suas ações alcançar patamares de abstração cada vez mais superiores.

Conforme as elaborações e reconstituições das representações em um todo se tornam cada vez mais eficazes e atingem níveis cada vez mais superiores, a reconstrução e elaboração e novas estruturas conduz o sujeito ao que Piaget considera como abstração refletida. Nesse nível de abstração ocorre o que chamamos por metareflexão, ou ainda, reflexão sobre reflexão. Nesse ponto, o sujeito elabora reflexões sobre as reflexões previamente elaboradas e chega ao nível da formalização do pensamento. Isso não torna a abstração empírica nula, porém ela tende a ser muito pequena quantitativamente se comparada ao início do processo. Logo, o processo reflexionante possibilita que sujeito faça construções de formas de pensamento cada vez mais elaboradas, enriquecidas pela sua ação sobre os objetos e sobre a coordenação de suas ações. A Figura 01 mostra através de um diagrama a organização das ideias sobre o processo de abstração apresentadas ao longo dessa seção. Durante a presente pesquisa foi observado que a evolução cognitiva dos sujeitos envolvidos com a proposta ocorreu de modo gradual, onde as diferentes formas de abstrações foram surgindo e incorporando novos elementos na qualidade do pensamento dos participantes.

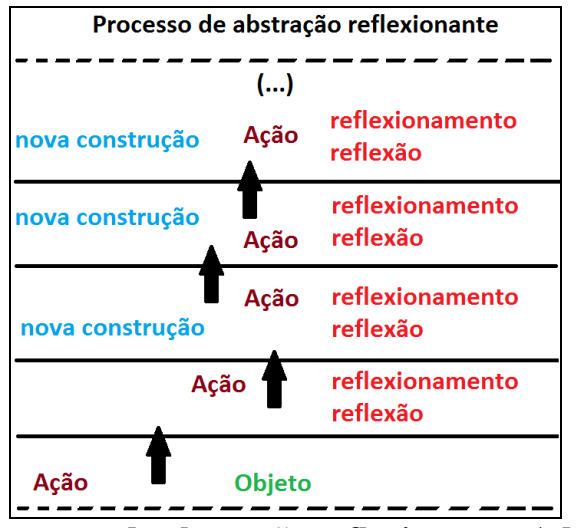

Figura 01: Esquema sobre o processo de abstração reflexionante. Adaptado de Becker (2012, p.38)

\section{Engenharia didática: proposta de trabalho}

Artigue (1996) aponta:

A engenharia didática vista como metodologia de pesquisa de investigação, caracteriza-se antes de mais nada por um esquema experimental baseado em realizações didáticas na sala de aula, isto é, na concepção, na realização, na observação e na análise de sequências de ensino. (Artigue, 1996, p.196)

Acreditamos que a engenharia didática possibilita ao professor repensar a sua prática docente enquanto atua em sala de aula e também nota-se que a realidade escolar torna-se cenário para reflexão, criação e encaminhamento de propostas inovadoras de 
ensino. Ao trabalhar utilizando esse método de ensino o professor pode se questionar se é possível que os alunos aprendam determinando conteúdo através de uma sequência de atividades que pode ser repensada e readequada durante a execução da proposta. Ao propormos a abordagem de situações-problema envolvendo modelagem matemática através das Cadeias de Markov, a engenharia didática ocorre através de quatro etapas ou fases:

Análise prévia (1) - Nessa fase nos questionamos como ocorre o ensino dos conteúdos propostos e quais os efeitos que isso implica na aprendizagem dos alunos. o pesquisador observa também quais são as dificuldades apresentadas pelos alunos perante esses conteúdos. Concepção do experimento, análise a priori e criação das hipóteses (2) - Criação da sequência de atividades que constituem o experimento. Formulação, por parte do professor, das hipóteses que serão possivelmente validadas durante a execução das atividades. Experimento (3) - Execução das atividades planejadas na anterior. Análise a posteriori (4) - Com base nas observações produzidas durante a fase da experimentação, o professor tenta validar ou não as hipóteses conjecturadas e assim validar o seu experimento didático.

Observamos que a engenharia didática pode se constituir em uma metodologia de trabalho cíclica, ou seja, o professor pode durante a execução do seu roteiro de atividades (fase 3) se deparar com novas dificuldades apresentadas pelos alunos e que não foram detectadas anteriormente (fase 1). Neste momento o professor pode redefinir também a sua concepção do experimento e criar hipóteses adicionais, ou ainda refutar alguma das hipóteses iniciais. Assim, a readequação da proposta metodológica visa a contribuir na construção e aprendizagem dos conceitos de matemática pelos alunos. $\mathrm{O}$ esquema apresentado na Figura 02 possibilita compreender melhor as fases que envolvem a engenharia didática e suas possíveis relações com a presente proposta de trabalho.

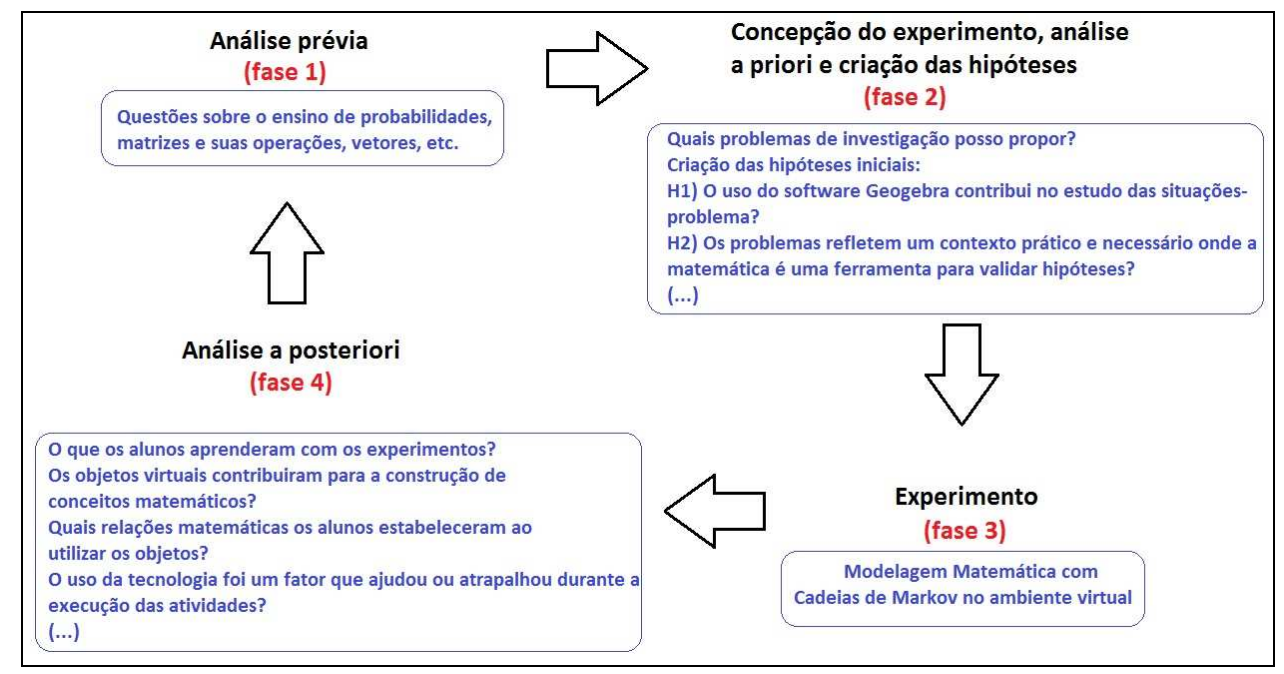

Figura 02: Esquema sobre a engenharia didática. Fonte: os autores.

\section{Procedimentos Metodológicos}

Para a realização dessa pesquisa foi observada uma amostra de 20 participantes, constituídos por alunos de graduação em licenciatura em matemática e professores de matemática da região de Passo Fundo (RS). A amostra foi participante de uma oficina pedagógica intitulada "Cadeias de Markov e Geogebra: modelagem matemática e 
possibilidades para a construção de conceitos através do uso de objetos virtuais" que ocorreu em um congresso na Universidade de Passo Fundo (UPF).

Inicialmente, a proposta consistiu em apresentar uma situação-problema onde através da matemática busca-se a construção de uma solução para a questão. $O$ problema consiste em analisar a situação: "Suponha que no ano 2000 a taxa de migração de uma cidade para o seu subúrbio seja de 5\%. E que durante o mesmo ano a taxa de migração entre o subúrbio e a cidade seja de 3\%. Se a população observada no ano 2000 foi de 600000 habitantes na cidade e no subúrbio foi de 400000 então qual a população estimada para o ano 2001?"

Observamos que o problema apresentado anteriormente mobiliza diferentes estruturas cognitivas na tentativa de resolvê-lo. O sujeito ao se deparar com esse tipo de situação-problema procura dentro de sua limitação estrutural assimilar o conteúdo e estabelecer relações que possam ser utilizadas na elaboração da solução. $O$ conhecimento matemático do assunto porcentagem permite ao sujeito mobilizar o pensamento na construção de uma possível solução para o problema.

O objeto construído no software Geogebra e apresentado na Figura 03 foi utilizado pelos alunos durante a execução das atividades e permitiu que a modelagem da situação-problema proposta no início dessa seção fosse possível de ser realizada. Com o auxílio do software Geogebra, desenvolvemos um objeto virtual onde foi possível perceber que os sujeitos envolvidos mobilizaram diferentes estruturas cognitivas em busca do objetivo de construir e interpretar a situação apresentada pelo problema inicial.

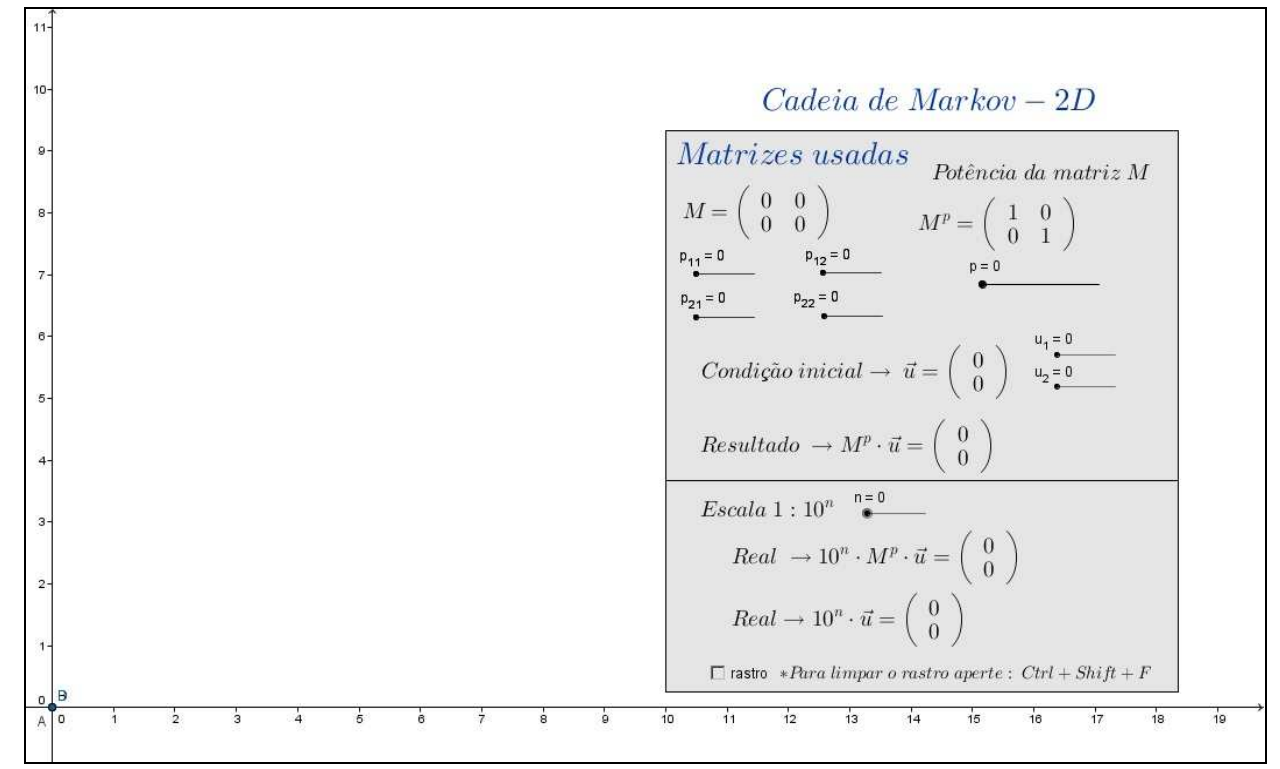

Figura 03: Interface do objeto virtual construído no Geogebra. Fonte: Arquivo pessoal.

Através do objeto o usuário tem a possibilidade de determinar as entradas da matriz de estado, a qual coordena o comportamento do fenômeno ao longo do experimento $^{2}$. O usuário também pode determinar o vetor correspondente às condições iniciais. Com o cálculo da potência da matriz pode-se verificar o que ocorre com vetor das condições iniciais ao longo do tempo. Ao querer determinar a estimativa da população para o ano de 2030, o objeto fornece subsídios necessários para essa resposta, conforme mostra a Figura 04. A população estimada para essa época será de

\footnotetext{
${ }^{2}$ Para maiores detalhes consulte Anton e Rorres (2012), Anton e Busby (2003), Kemeny e Snell (1976), Behrends (2000).
} 
aproximadamente 394000 para a cidade e de aproximadamente 607000 para o subúrbio. Com a habilitação da ferramenta "rastro" é possível visualizar o que ocorre com a variação da população ao longo do fenômeno migratório entre cidade e subúrbio.

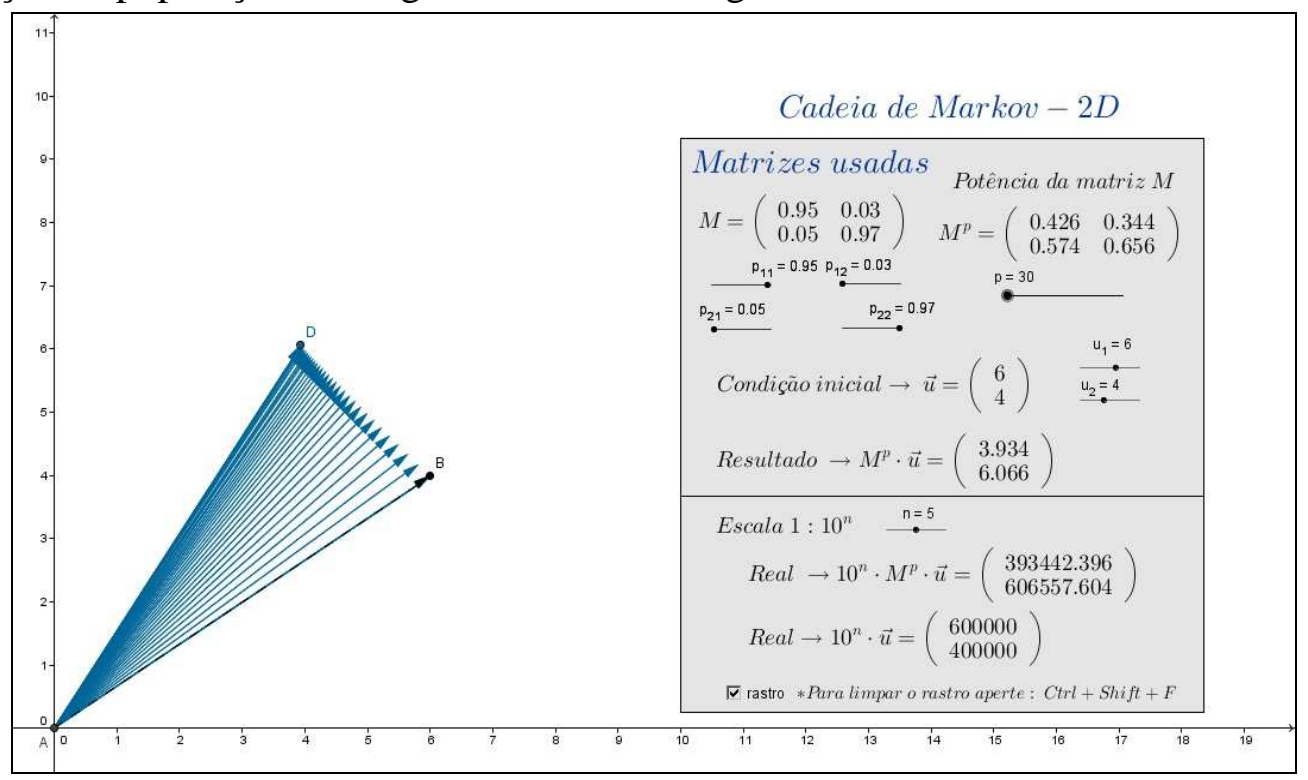

Figura 04: Estimativa da população no ano de 2030. Fonte: Arquivo pessoal.

Portanto, através dos princípios propostos pela engenharia didática foi possível construir uma sequência de dezoito atividades ${ }^{3}$ envolvendo a análise da situaçãoproblema inicial. A oficina pedagógica ocorreu com os alunos ao longo de três momentos: $\left(1^{\circ}\right)$ Motivação: problema inicial; $\left(2^{\circ}\right)$ Explorando o objeto virtual e $\left(3^{\circ}\right)$ Explorando a cadeia de Markov. Em cada uma das etapas os sujeitos se deparavam com questionamentos que colocavam em prova as suas hipóteses e conjecturas elaboradas.

Verificamos que o conjunto de atividades propostas constitui uma fonte inicial para a compreensão de como é possível através de uma situação-problema construir um cenário que possibilite a elaboração e construção de conceitos matemáticos. A tecnologia, presente através do recurso utilizado pelos alunos, possibilita que através do exercício sucessivo da abstração seja possível aprender matemática, uma vez que as atividades exigiam do sujeito a constante ação sobre o objeto de investigação.

\section{Análise da produção dos alunos}

À luz da teoria da abstração reflexionante de Piaget, a produção dos alunos ao longo da oficina pedagógica nos conduz para uma reflexão sobre a construção dos conceitos matemáticos abordados durante a sequência de atividades. Inicialmente, apontamos que a leitura dos alunos perante a situação-problema produziu diferentes percepções sobre o contexto. No exemplo da Figura 05, apontamos o exercício da abstração empírica quando os alunos mencionam o assunto porcentagem como envolvido na situação. Ao citar assuntos tais como: função exponencial, progressão geométrica, regra de três, situação-problema, os alunos exercitam a chamada abstração pseudo-empírica, caracterizada anteriormente por atribuir qualidades não perceptíveis nos objetos para os mesmos.

\footnotetext{
${ }^{3}$ Atividades disponíveis em: https://dl.dropboxusercontent.com/u/60260993/atividades_markov_2D.pdf
} 


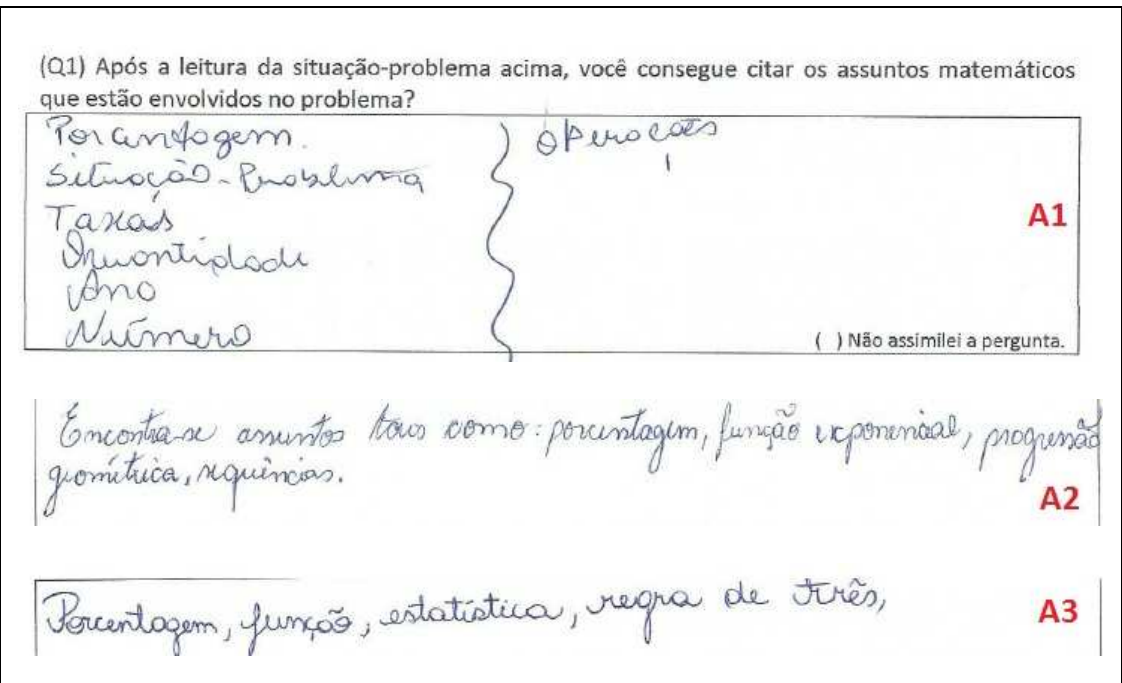

Figura 05: Respostas iniciais dos alunos A1, A2 e A3. Fonte: Arquivo pessoal.

Ao longo da sequência de atividades, nota-se que a maioria dos alunos foi gradualmente construindo e elaborando os métodos para a resolução do problema proposto, caracterizando um pleno exercício de abstração. Notou-se que a abstração reflexionante ocorreu em diversos alguns casos, seguida de tomada de consciência produzindo a construção do conceito através da abstração refletida, uma vez que o sujeito estava coordenando as suas ações em pensamento para comunicar o resultado matemático, conforme se pode observar nas respostas que aparecem na Figura 06.

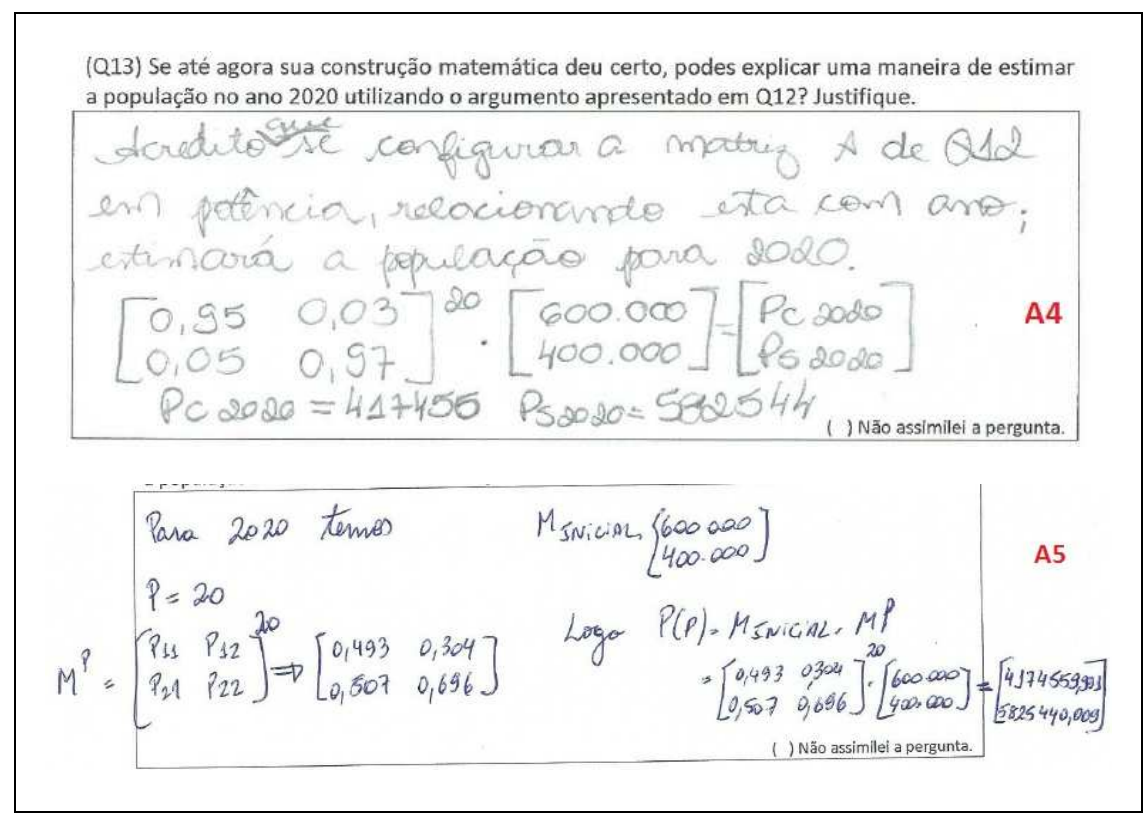

Figura 06: Respostas com tentativa de generalização dos alunos A4 e A5. Fonte: Arquivo pessoal.

Ao final da sequência de atividades, questionamos os sujeitos envolvidos quanto ao uso do objeto virtual proposto para a realização da oficina pedagógica. Destacamos que dentre os questionamentos propostos, procuramos também investigar se os sujeitos concebiam o seu possível uso em sala de aula para a abordagem de diversos conceitos matemáticos com os alunos. Dentro da amostra pesquisada de vinte sujeitos, quinze se manifestaram tal como está exposto na Figura 07 onde se percebe o notável interesse por parte dos professores (e futuros professores) em trazer para dentro da sala de aula 
contextos que possibilitam partir de abstrações empíricas e chegar até abstrações refletidas, agindo sobre os objetos abstratos que a matemática propõe, mas que através do uso da tecnologia se possibilite construir conceitos matemáticos de forma eficiente e eficaz.

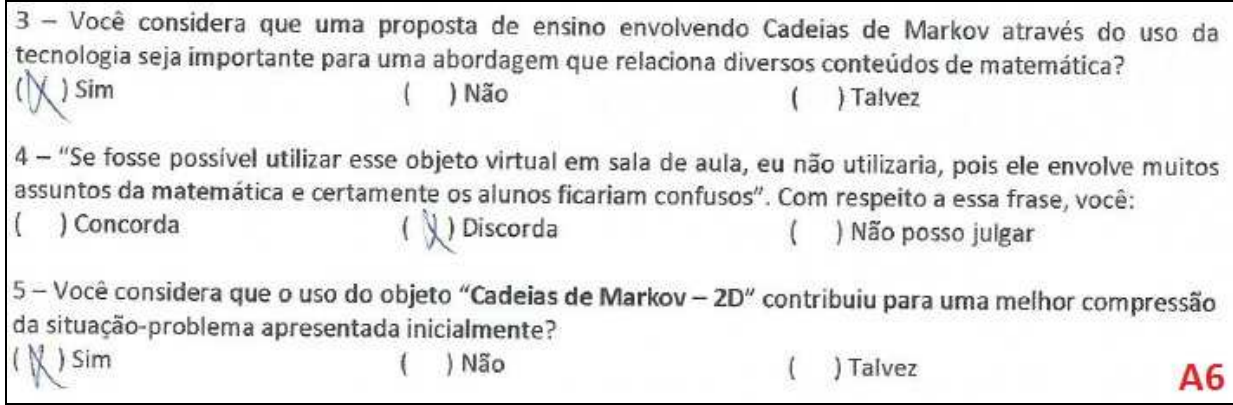

Figura 07: Resposta do aluno A6 no questionário final. Fonte: Arquivo pessoal.

\section{Resultados parciais da pesquisa}

Consideramos que o estudo das chamadas Cadeias de Markov é uma oportunidade de abordar e relacionar diversos assuntos de matemática que são apresentados isoladamente dentro da disciplina de matemática, tais como matrizes (e suas operações), sistemas lineares, vetores e probabilidade. $\mathrm{O}$ uso do objeto virtual apresentado nesse texto não se limita apenas para um tipo de público alvo, os professores de nível básico podem estender o seu uso para a abordagem de situações-problema também no ensino superior.

Conforme destacado anteriormente, o encaminhamento de uma proposta de ensino envolvendo Cadeias de Markov através de uma metodologia envolvendo os princípios da engenharia didática permite ao professor relacionar e abordar diversos assuntos matemáticos e também suas aplicações em outras áreas do conhecimento. $\mathrm{O}$ uso da tecnologia para a realização da proposta considera-se essencial, pois percebemos ao longo das atividades, que ela é uma ferramenta catalisadora no processo de aprendizagem. Ao longo do processo, verificou-se que o sujeito envolvido com as atividades propostas percebeu além da relevância do estudo desse tema, dando-se conta (abstração reflexionante) que é possível relacionar a matemática envolvida nas Cadeias de Markov com diversas outras aplicações da ciência, tornando a matemática uma disciplina aplicada e necessária para a modelagem e interpretação dos diversos fenômenos que o cerca.

\section{Referências}

BECKER, F. Epistemologia do Professor de Matemática. Petrópolis-RJ: Vozes, 2012.

ANTON, H.; RORRES, C. Álgebra Linear com aplicações. $10^{\circ}$ Ed. Porto Alegre, Bookman, 2012.

ANTON, H.; BUSBY. R. C. Contemporary Algebra. Hoboken, New Jersey: Wiley. 2003.

BEHRENDS, E. Introduction to Markov Chains: with special emphasis on rapid mixing. Berlin: Vieweg. 2000.

BIASI, H.; DOMENECH, M. Ferramenta de Software para o auxílio ao processo de Ensino-Aprendizagem de Métodos Estocásticos. Unoesc \& Ciência - ACET, 
Joaçaba, v. 3, n. 1, p. 37-46, jan./jun. 2012. Disponível em: http://editora.unoesc.edu. br/index.php/acet/article/view/1103/pdf Acesso em 15/03/2014.

BRASIL. Ministério da Educação (MEC), Secretaria da Educação Média e Tecnológica (Semtec). Parâmetros Curriculares Nacionais para o Ensino Médio. Brasília, 2000. Disponível: http://portal.mec.gov.br/seb/arquivos/pdf/ciencian.pdf. Acesso em 20/04/2014.

FERREIRA, S. R. I. Aplicações de matrizes no ensino médio. Dissertação de mestrado. Universidade de São Paulo. USP. 2013. Disponível em: http://www.teses. usp.br/teses/disponiveis/55/55136/tde-07062013-100316/en.php.Acesso em 20/03/2014.

KEMENY, J. G.; SNELL, J. L. Finite Markov Chains. New York: Springer. 1976.

MONTANGERO, J. \& MAURICE-NAVILLE, D. Piaget ou a inteligência em evolução. Porto Alegre. Alegre: Artmed, 1998.

PIAGET, J. Abstração reflexionante; relações lógico-aritméticas e ordem das relações espaciais. 1977. Porto Alegre: Artes Médicas. Tradução de Fernando Becker e Petronilha B. G. da Silva. 1995.

SILVA, C. E. V. Aplicações da álgebra linear nas Cadeias de Markov. Dissertação de mestrado. Programa de Mestrado Profissional em Matemática em Rede Nacional (PROFMAT). 2013. Disponível em: http://bit.profmat-sbm.org.br/xmlui /bitstream/handle/123456789/519/2011_00417_CARLOS_EDUARDO_VIT\%C3\%93R IA_DA_SILVA.pdf?sequence=1. Acesso em 24/03/2014. 